\title{
Narrativas y solidaridad de las redes transnacionales de derechos humanos en Argentina*
}

\section{Narratives and Solidarity of Transnational Human Rights Networks in Argentina}

\author{
Marianela Scocco \\ (D) https://orcid.org/0000-0002-1309-1613 \\ ISHIR-CONICET/Universidad Nacional de Rosario, Argentina \\ mariascocco@gmail.com
}

Resumen: Las redes transnacionales en defensa de los derechos humanos se constituyeron en vehículos clave en la transmisión de la cultura de los derechos humanos para los organismos surgidos en Argentina entre 1974-1979. Proveyeron a los denunciantes nacionales un vocabulario específico para ejercer sus demandas basado en lo que se ha denominado como "narrativa humanitaria", diferenciándose de la "narrativa revolucionaria" que había signado la defensa de presos políticos en la dictadura anterior (1966-1973). En este artículo analizo, en clave comparativa, esa defensa de presos políticos y de los organismos de derechos humanos posteriores, poniendo atención en el cambio que significó el traslado de una narrativa a otra. Por otro lado, tomando un caso local, examino el hecho de que los organismos de la ciudad de Rosario se vieron privados del acceso a la financiación, información e influencia

* Este artículo es la reelaboración de una ponencia presentada en el III Coloquio Internacional sobre Violencia Política en el Siglo XX / IV Jornadas de la RER, Escuela de Historia, Facultad de Humanidades y Artes de la Universidad Nacional de Rosario, entre el 24 y 26 de abril de 2019.

Cómo citAR: Scocco, M. (2020). Narrativas y solidaridad de las redes transnacionales de derechos humanos en Argentina. Secuencia (108), e1807. Dor: https://doi.org/10.18234/secuencia.v0i108.1807

cC Esta obra está protegida bajo una Licencia Creative Commons Atribución-NoComercial 4.0 Internacional. 
que la transnacionalización del reclamo y el impacto internacional proveyó a los organismos de la capital del país.

Palabras clave: narrativa revolucionaria; narrativa humanitaria; defensa; solidaridad; derechos humanos.

Abstract: Transnational networks to defend human rights became key vehicles in the transmission of human rights culture for organizations that emerged in Argentina between 1974 and 1979. They provided national complainants with a specific vocabulary to exercise their demands based on what has been called the "humanitarian narrative," differentiating themselves from the "revolutionary narrative" that had marked the defense of political prisoners in the previous dictatorship (1966-1973). In this article I analyze, by way of comparison, this defense of political prisoners and subsequent human rights organizations, focusing on the change signified by the transfer from one narrative to another. I then use a local case to examine the fact that organizations in the city of Rosario were deprived of access to the financing, information, and influence that the trans-nationalization of claims and international impact provided for those in the capital.

Keywords: revolutionary narrative; humanitarian narrative; defense; solidarity; human rights.

Recibido: 21 de enero de 2020 Aceptado: 19 de mayo de 2020

Publicado: 17 de diciembre de 2020

\section{INTRODUCCIÓN}

Dara fines de la década de 1960, se evidenciaba a nivel internacional pero 1 también latinoamericano, una creciente ola de movilización política y social. Se nutría de diferentes alineamientos y procesos revolucionarios a nivel mundial (el choque chino-soviético, la primavera de Praga, los procesos de descolonización como el argelino, el Mayo Francés, la resistencia a la intervención estadunidense en Vietnam y, sobre todo, la revolución cubana). En 
parte derivada de ello, en Argentina emergió una izquierda que se sustentaba en una lectura de la realidad nacional distinta a la de la izquierda tradicional, orientada a la revolución socialista y a conformar alianzas centradas con la clase obrera y los campesinos pobres. ${ }^{1}$

El año 1969 fue un momento bisagra tanto por las movilizaciones callejeras que se produjeron en varias ciudades del país, como por las respuestas represivas que generaron. La más conocida fue el Cordobazo, una insurrección popular sucedida en la ciudad de Córdoba el 29 y 30 de mayo. En otras ciudades como Rosario, la reacción popular también se expresó bajo la forma de levantamientos urbanos masivos. Estos hechos evidenciaron el surgimiento de una tendencia insurreccional de masas, mientras se empezaba a descreer de la eficacia de los canales institucionales (partidos políticos tradicionales y sindicatos).

En ese contexto, comenzaron a surgir y/o consolidarse diversas organizaciones político-militares que basaban su estrategia en la construcción de un foco guerrillero que asumiera la lucha armada contra el gobierno. Las dos organizaciones más destacadas fueron, desde el peronismo, Montoneros y, desde la izquierda marxista, el Partido Revolucionario de los Trabajadores y su brazo armado, el Ejército Revolucionario del Pueblo (PRT-ERP). No obstante, hubo también distintas organizaciones políticas de izquierda que discutieron y rechazaron explícitamente la estrategia de la lucha armada.

Derivado de la agudización del conflicto social, a partir de entonces se produjo un significativo aumento de la cantidad de los presos políticos en el periodo 1969-1973, pertenecientes a las organizaciones armadas y no armadas, pero también a militantes populares, estudiantiles y gremiales. Frente a ello surgieron diversas comisiones en defensa de dichos presos, con reconocidos vínculos con esas organizaciones. Estas comisiones adoptaron una "narrativa revolucionaria” en relación con la defensa de los presos políticos, que se basó en la denuncia de la cárcel como principal estrategia represiva de la dictadura de la "Revolución Argentina" (1966-1973) y ponía el foco en la condición de "políticos" de los presos. Luchaban por el poder del Estado y suponían que sus demandas sólo podrían ser satisfechas por otro régimen político, en una tarea mucho más radical de trasformación social.

\footnotetext{
${ }^{1}$ Para mayor profundidad sobre la izquierda y sus diferentes conceptualizaciones véase Mangiantini (2018).
} 
El plan sistemático de aniquilamiento de la última dictadura militar (1976-1983), en contraste, consistió en secuestros clandestinos, apropiación de menores, torturas, asesinatos y desapariciones forzadas de militantes populares, dirigentes sindicales y personas opositoras en general. El cambio en la magnitud de la represión implicó también un cambio en las estrategias defensivas. ${ }^{2}$ En este sentido, las redes transnacionales en defensa de los derechos humanos proveyeron a los denunciantes nacionales de un léxico, un vocabulario y métodos de sistematización de la información específicos para ejercer sus demandas con base en lo que se ha denominado como "narrativa humanitaria". Diferente a la matriz política-ideológica en que se asentó la denuncia de la cárcel en el periodo anterior, esta nueva narrativa privilegiaba la descripción de los secuestros y de las características de los represaliados resaltando el carácter universal del reclamo, produciendo un giro caracterizado por la despolitización de las demandas y el abandono de la retórica revolucionaria.

\section{LA NARRATIVA REVOLUCIONARIA EN LAS COMISIONES DE PRESOS POLÍTICOS}

Los primeros momentos de la década de 1970 constituyeron, por varios motivos, un punto de inflexión en la defensa de presos políticos que, a partir de entonces, adquirirá una presencia y una consistencia política, corporativa y profesional aún mayor que en la década anterior. La solidaridad con los detenidos políticos tiene larga data en Argentina, pero fue en este contexto de incremento de la represión y de la población carcelaria que se produjo la creación de organismos dedicados exclusivamente a este problema.

En este sentido, me parece importante definir la categoría de "presos políticos" que incluye a los detenidos por razones políticas, gremiales, estudiantiles y sociales. Lo que distinguía a un preso político de un preso común era la finalidad que lo llevaba a accionar de determinada manera. En ambos

2 El uso de la adjetivación "defensista" para referirme a la acción de defensa que llevaron a cabo diversas personas, grupos u organizaciones, tanto en defensa de presos políticos como de los derechos humanos en general, es una categoría nativa que proviene de la defensa de presos políticos de la primera mitad de los setenta, que en cierta forma se extendió de los abogados a las organizaciones. Es un término que procede del derecho y puede referir a los abogados defensores de cualquier litigio. En la historia argentina contemporánea existe una larga tradición defensista que comienza desde principios siglo $\mathrm{xx}$. 
casos se violentaba la ley, pero la intencionalidad en un preso común era aprovecharse personalmente de esa vulneración de la ley y, en el otro, era una intencionalidad política que estaba por encima del objetivo individual. Por eso, más allá de la justeza o no de la acción, lo que definía que fuera un preso político era el propósito por el cual había cometido tal acción (Bacci; Carnovale y Oberti, 2010). Por otro lado, los abogados y las organizaciones defensistas apelaron a la categoría de preso político como forma de establecer un criterio de distinción simbólico respecto de los presos comunes. Esta diferenciación persiguió una finalidad pragmática orientada a obtener ciertas solicitudes o tratos especiales en las condiciones de detención (Chama, 2014) y a adecuar las estrategias jurídicas para las defensas.

Las comisiones de solidaridad y apoyo a los presos políticos que surgieron en este contexto tenían reconocidos vínculos con algunos partidos políticos y organizaciones político-militares. Denominadas "comisiones de presos", "comisiones de familiares" o "comisiones de solidaridad" por sus contemporáneos, denunciaban el uso de la cárcel como principal estrategia represiva y sus derivaciones: persecuciones, condiciones de encierro inhumanas, torturas y traslados disciplinatorios. De variada composición, con diferentes grados de institucionalización, las comisiones de presos representaban la forma organizativa típica de la "Revolución Argentina". Eran espacios compartidos por familiares y militantes $y$, aunque en principio mantenían vínculos con determinados partidos u organizaciones políticas, la pluralidad ideológica estaba presente en la mayoría de estas organizaciones.

Las acciones por apoyo, solidaridad y defensa a detenidos políticos se intensificaron especialmente en la etapa 1971-1973 en función del crecimiento numérico de los presos políticos y la transformación cualitativa de la represión durante la última etapa de la dictadura. Para el año 1971 al menos, se puede reconocer ya la existencia de distintas agrupaciones defensistas de presos políticos de alcance nacional. En estas organizaciones, abocadas a la solidaridad con los presos políticos y a la defensa de los derechos humanos -aunque todavía no aparecía en el lenguaje de la época este sintagma, excepto en el Foro de Buenos Aires por la Vigencia de los Derechos Humanos-, se destacaban los familiares de las personas detenidas, los compañeros de militancia (en ocasiones también parejas, sobre todo las mujeres) y algunos abogados comprometidos en la defensa legal de los militantes. Como afirma Alonso (2017): "Los repertorios discursivos de los escasamente visibles agrupamientos previos a 1974 no se articulaban sobre la noción de 'derechos humanos', sino que 
se planteaban más generalmente como denuncia de la represión sufrida por el pueblo" (p. 104).

Eidelman (2009) sugiere el siguiente listado de las organizaciones de alcance nacional, la mayoría constituidas a lo largo del año 1971 para la defensa y solidaridad con presos políticos, gremiales y estudiantiles:

la Comisión de solidaridad con los presos políticos y el cuerpo de abogados de la CGT de los Argentinos; la Asociación Gremial de Abogados; la Agrupación de Abogados Peronistas; la Comisión Peronista de Ayuda a los Presos Políticos (coppap); la Organización de Solidaridad con los Presos Políticos, Estudiantes y Gremiales (ospPeg) [...]; la Comisión de Familiares de Presos Políticos, Estudiantiles y Gremiales (CofAPpeg ); el Movimiento Nacional contra la Represión y la Tortura y el Foro de Buenos Aires por la Vigencia de los Derechos Humanos (p. 14).

Los pronunciamientos, solicitadas y comunicados de repudio de abogados, sindicatos, agrupaciones estudiantiles, partidos políticos y organizaciones político-militares se multiplicaron en ese contexto. Las denuncias aludían al endurecimiento de la legislación represiva, a los procedimientos y detenciones llevados adelante por las fuerzas de seguridad, al aumento del número de presos políticos, a las rigurosas condiciones de detención, a los apremios ilegales y torturas sobre los cautivos. Con el tiempo también se incorporaron los reclamos por los secuestros y desapariciones, aunque se trataba todavía de hechos puntuales.

Esta función denuncialista fue asumida también por algunos abogados. Estas denuncias procuraron canalizarse a través de medios de comunicación. De esta forma, la acusación pública con documentación de casos de torturas y apremios ilegales así como de las condiciones carcelarias y la presentación de listas sobre secuestros, asesinatos y detenciones, buscaban generar un impacto en la opinión pública con el objetivo de reforzar una conciencia antirrepresiva y antidictatorial. Asimismo, la decisión de estos profesionales por recurrir a un actor extrajudicial, como la prensa, para canalizar sus reclamos, manifestaba el rechazo a un poder judicial claramente subordinado al poder militar (Chama, 2010). Además, la denuncia pública de las detenciones ilegales persiguió un fin más urgente: legalizar rápidamente al detenido para evitar que este fuera objeto de castigos y apremios por parte de las fuerzas de seguridad. 
Por otro lado, las organizaciones defensistas llevaron a cabo la realización y distribución de algunos informes, folletos y/o publicaciones, como los informes de la Comisión de Familiares de Detenidos (COFADE, 1969), ${ }^{3}$ la Comisión de Familiares de Presos Políticos, Estudiantiles y Gremiales (Cofappeg, 1972) $)^{4}$ y el Foro de Buenos Aires por la Vigencia de los Derechos Humanos (1973). ${ }^{5}$

El primero, el Libro negro de la Casa Rosada, que editó COFADE en agosto de 1969, revelaba la represión y la censura que la dictadura imponía a la población, reclamando la libertad de los presos políticos. Su título resignificaba el del informe de la comisión creada por la "Revolución Libertadora" para investigar al peronismo tras el golpe de Estado de 1955 (Crenzel, 2008). CofADE (1969) proclamaba que: "El régimen capitalista no puede subsistir sin detener, sin torturar, sin quebrar a los dirigentes populares" (p. 45).

Chama (2014) sostiene que:

Este tipo de argumentaciones, que buscaban establecer una relación directa entre el sistema socioeconómico y la represión gubernamental, sería uno de los tópicos centrales que grupos defensistas de mayor envergadura nacidos durante los primeros setenta, como la Asociación Gremial de Abogados o la Comisión de Familiares de Presos Políticos, Estudiantiles y Gremiales [CofAPPEG], utilizarían en los años subsiguientes (p. 127).

${ }^{3}$ Cofade constituyó el primer nucleamiento defensista a nivel nacional, próximo al peronismo, conformado por familiares, abogados y activistas, en respuesta a la aplicación del Plan Conintes. Según Chama la organización, con una trascendencia pública de casi una década, tuvo dos grandes momentos. El primero, entre 1960-1963, motorizado por un reducido grupo de familiares que buscaron mantener un criterio de autonomía y prescindencia partidaria y, el segundo, entre 1964-1970, orientado por un núcleo de militantes identificados con una de las vertientes más combativas del peronismo, el Movimiento Revolucionario Peronista (MRP), liderado por Gustavo Rearte. Para mayor información sobre CofADE, véase Chama (2014).

${ }^{4}$ La CofAppeg comenzó a funcionar desde mediados del año 1971 en ciudades importantes de Argentina. En sus orígenes, esta Comisión se autodefinía como autónoma, es decir, como no dependiente de ninguna otra entidad o agrupación, aclarando que contaba con sus propios fondos económicos, no obstante tenía reconocidos sus vínculos con el PRT-ERP (Scocco, 2021). Según Eidelman (2009), en Buenos Aires surgió recién en 1972, producto de una división entre familiares de presos de diferentes organizaciones político-militares peronistas y marxistas.

${ }^{5}$ El Foro de Buenos Aires por la Vigencia de los Derechos Humanos se constituye en dicha ciudad en octubre de 1971. Era un espacio conformado principalmente por figuras públicas para la difusión más amplia posible de la situación de los presos políticos. 
El texto informaba sobre casos de las torturas recibidas por militantes políticos, principalmente peronistas y de las Fuerzas Armadas de Liberación (FAL); los consejos de guerra implementados en 1969 y la represión sufrida por la CGT de los Argentinos.

Otro informe se denominó Torturas en Argentina, fue realizado por la Cofappeg de la provincia de Córdoba y publicado en julio de $1972 .{ }^{6}$ Con más de 50 páginas el informe denunciaba los apremios ilegales a que eran sometidos los presos políticos. El trabajo contenía una declaración de principios de la organización y reunía testimonios de presos políticos detenidos centralmente durante 1971 en Buenos Aires, Córdoba, Rosario, Tucumán, La Plata, Mendoza, Buenos Aires, Santiago del Estero y Corrientes. Estaba basado en la denuncia pública efectuada por el Foro de Buenos Aires por la Vigencia de los Derechos Humanos en enero de 1972.

Antes de la asunción del nuevo gobierno tras las elecciones democráticas de 1973, el Foro de Buenos Aires por la Vigencia de los Derechos Humanos (1973) preparó un informe titulado: Proceso a la explotación y a la represión en la Argentina, publicado en mayo de ese año. Este informe, de 222 páginas, constituía una suerte de resumen de los principales hechos represivos revelados por el Foro, consumando una lista muy completa de los secuestros sucedidos en esos años. Esta publicación sostenía en su prólogo que: "La represión motivó un vasto movimiento de protesta y de denuncia. Numerosos organismos de solidaridad en todo el país: grupos políticos, gremiales, estudiantiles, religiosos, familiares, de presos, abogados, periodistas y otros profesionales -y este Foro- denunciaron sistemáticamente a través de diversos medios las dimensiones que alcanzaban la explotación y la represión" (p. 6).

A la vez que advertía que existía una relación entre la opresión propia del sistema y la represión extraordinaria que se había expandido en los últimos años. Por último, el prólogo finalizaba afirmando que

una nueva conciencia se está levantando sobre el país y sus problemas: conciencia de que los derechos humanos son sagrados e inalienables [...] Millones de argentinos votaron también por la inmediata libertad de quienes, de una $\mathrm{u}$ otra forma lucharon contra el régimen, y por una exhaustiva investigación que individualice y condene a los responsables directos, a sus instigadores, y

${ }^{6}$ Según Crenzel (2008) se editaron 3000 ejemplares, los cuales fueron distribuidos en quioscos para su venta. 
encubridores de los crímenes que el régimen, a través de la Fuerzas Armadas y de la policía, cometió (p. 7).

Con las noticias de la represión, el informe intercalaba temas de otro orden que daban cuenta de una mirada más integral acerca de los derechos universales de los pueblos, lo que posteriormente se conoció como la "agenda ampliada" de los derechos humanos. Entre estos temas incluía la censura, la vivienda, la educación, la salud y la explotación de los trabajadores.

Estos informes realizados por organizaciones defensistas de los presos políticos presentaban claras diferencias con los reclamos por los derechos humanos que se expandieron una década después, sobre todo por las posturas político-ideológicas que reivindicaban. Estas publicaciones podían tener como interlocutores a las autoridades dictatoriales en función de reclamos puntuales y exigiendo medidas concretas pero se dirigían principalmente al pueblo del que se identificaban como miembros y al que querían sumar a la lucha, con el llamado a la solidaridad y a la movilización social. Además, compartían la narrativa de la militancia revolucionaria (Crenzel, 2008). Alonso (2011) sostiene que en el horizonte de expectativas de estas agrupaciones, sólo la revolución social y la liberación nacional podían resolver los problemas planteados. En cuanto a los repertorios discursivos, los enunciados no se articulaban en torno a la noción de "derechos humanos", sino que se planteaban más generalmente como denuncia a la represión sufrida por el pueblo. Sin embargo, al menos en el último informe ya aparecía una noción de que "los derechos humanos son sagrados e inalienables" (Foro de Buenos Aires por la Vigencia de los Derechos Humanos, 1973, p. 7), al tiempo que estos informes permiten observar continuidades con el movimiento de derechos humanos posterior, sobre todo en las denuncias, especialmente en aquellas relacionadas con los apremios ilegales recibidos por los secuestrados/detenidos.

Algo similar sucedió en Uruguay, de acuerdo con lo analizado por Vania Markarian (2004) quien sostiene que algunos sectores más radicalizados de la izquierda uruguaya creían que el problema de los presos políticos debía ubicarse en términos de lucha de clases. Aunque el golpe de Estado en Uruguay (1973) ocurrió con anterioridad a la última dictadura militar argentina y la estrategia represiva se basó en arrestos masivos; largas sentencias a los detenidos condenados; torturas; asesinatos $y$, por lo general, víctimas claramente identificadas - a diferencia de Argentina y con cifras menores a esta 
última-, ${ }^{7}$ la gran mayoría de los grupos y partidos de izquierda y de los exiliados uruguayos empezaron a usar el lenguaje de los derechos humanos recién hacia fines de 1976, en parte por la influencia de las redes transnacionales en esta materia.

\section{LA ADOPCIÓN DE LA NARRATIVA HUMANITARIA EN EL MOVIMIENTO DE DERECHOS HUMANOS ARGENTINO}

Desde inicios de los años setenta a partir del activismo por los derechos civiles para las minorías étnicas, del movimiento feminista, de grupos de oposición a la guerra de Vietnam y al Apartheid, además de la sensibilidad y empatía para con los perseguidos que despertaron las crueles dictaduras del Cono Sur, se conformaron diversas organizaciones y redes transnacionales de defensa de los derechos humanos, que pronto alcanzaron una presencia destacada en América Latina. Esas redes estaban formadas por estructuras de conexiones flexibles, sin jerarquías internas y con distinta intensidad de vinculación entre sus componentes (Keck y Sikkink, 2000). Había organizaciones de carácter diverso: organizaciones no gubernamentales; instituciones estatales y dependencias de organismos gubernamentales internacionales, como el Alto Comisionado de las Naciones Unidas para los Refugiados (ACNUR), la Comisión Interamericana de Derechos Humanos (CIDH) de la Organización de Estados Americanos (OEA) y la Comisión de Derechos Humanos (CDH) de la Organización de las Naciones Unidas (ONU). Organizaciones como Amnesty International (AI), fundada en 1961, recibieron un reconocimiento mundial en la década del setenta, momento en que el cual se fundaron otras organizaciones significativas como Human Rigths Watch (1978). Interesa destacar que una parte importante del activismo humanitario estuvo sustentado en organismos religiosos, con iglesias de diverso signo (católicas, protestantes, ecuménicas y judías).

Los exiliados de Argentina recurrieron a estas organizaciones y la denuncia en el exterior fue calando poco a poco en el país, socavando el cerco de la censura. De esta manera, los organismos internacionales y los reclamos en el exterior tuvieron una significativa influencia en el surgimiento de organi-

${ }^{7}$ Para un análisis en forma comparada de las estrategias represivas de ambas dictaduras véase Scocco (2010). 
zaciones similares en el país, en un momento en el que el cercenamiento del espacio público contribuyó a explicar la imposibilidad de que las denuncias fueran gestadas por organizaciones de representación como las agrupaciones armadas, los partidos políticos y los sindicatos, que se transformaron en blanco directo de la represión. Alison Brysk (1994) sostuvo que, en un contexto nacional que presentaba una estructura de oportunidades políticas muy restringidas, los organismos y familiares optaron por incitar la atención en el extranjero como una forma de saltar el cerco impuesto por el régimen militar y lograr una presión que pudiera frenar la represión.

Es conocida la lista de ocho organismos de derechos humanos emergentes en el período 1974-1979 en Argentina, ${ }^{8}$ algunos de los cuales ya existían al momento de producirse el golpe de Estado en 1976. En esta lista se incluye a la Liga Argentina por los Derechos del Hombre (LADH), la organización más antigua (1937), por su tarea realizada en la colaboración con la organización de los familiares de detenidos y desaparecidos. Sin embargo, los que efectivamente se habían creado en la coyuntura inmediatamente anterior a la dictadura eran el Servicio, Paz y Justicia en América Latina (SERPAJ) (1974); la Asamblea Permanente por los Derechos Humanos (APDH) (1975) y el Movimiento Ecuménico por los Derechos Humanos (MEDH) (1976). No obstante, estas organizaciones no lograron canalizar las demandas de los familiares directamente afectados por la represión, quienes formaron nuevos organismos durante los años de la última dictadura: Madres de Plaza de Mayo (1977); ${ }^{9}$ Abuelas de Plaza de Mayo (1977) ${ }^{10}$ y Familiares de Desaparecidos y Detenidos por Razones Políticas (1976), incluyendo la aparición de la agrupación HIJos ${ }^{11}$ que surgió en la década del noventa. También se formó después del golpe de Estado el Centro de Estudios Legales y Sociales (CELS), creado en el año 1979 por un grupo de abogados. Todas esas agrupaciones surgieron en la Capital Federal y registran acciones continuas desde su aparición hasta la actualidad, aunque no tuvieron réplicas exactas en otras ciudades del país o en el exterior.

${ }^{8}$ Para mayor información sobre estos organismos, véase Alonso (2014).

${ }^{9}$ En 1986 se produjo una división en la Asociación Madres de Plaza de Mayo, conformándose la Asociación Madres de Plaza de Mayo Línea Fundadora.

${ }^{10}$ Para el caso de Abuelas de Plaza de Mayo véase Laino Sanchis (2020). El autor sostiene que entre los múltiples factores que influyeron en la independencia de este organismo de Madres de Plaza de Mayo, su espacio de origen, uno fue la progresiva vinculación directa con organizaciones extranjeras.

${ }^{11}$ Hijos por la Identidad y la Justicia contra el Olvido y el Silencio. Organismo de derechos humanos conformado por hijos de víctimas del terrorismo de Estado argentino. 
Según Emilio Crenzel (2013), las redes transnacionales se constituyeron en vehículos clave en la transmisión de la cultura de los derechos humanos a los organismos de familiares y de derechos humanos de Argentina. Fueron estas organizaciones las que

proveyeron a los denunciantes locales de un léxico y un vocabulario específicos para ejercer sus demandas basado en lo que Thomas Laqueur ha denominado la "narrativa humanitaria". Ésta [...] Privilegiaba la descripción fáctica, realista y en detalle de los secuestros, las torturas padecidas, las características de los lugares de cautiverio, la presentación de los nombres de las víctimas, sus edades y sexos, nacionalidades, creencias religiosas, ocupaciones y profesiones y, cuando se conocían, los nombres de los perpetradores. [...] En paralelo, en base a estas variables sociodemográficas y socioeconómicas, ajenas a la matriz política en que se basó la represión, las redes trasnacionales clasificaban y presentaban a los desaparecidos presos y asesinados. Procuraban, de este modo, reconstruir la materialidad de los crímenes y elaborar una verdad basada en pruebas desechando las referencias a los compromisos políticos e ideológicos de quienes padecieron y perpetraron las violaciones así como de las causas y el contexto histórico-político en los que tuvieron lugar (p. 77).

Así, siguiendo a Crenzel, además del cambio coyuntural que significó la nueva dictadura, la influencia cultural de estas redes modificó la narrativa sobre la represión hasta entonces dominante en el país, al proponerla como un enfrentamiento entre víctimas y victimarios, desplazando la matriz de la lucha de clases o la antinomia entre el pueblo y la oligarquía, predominantes entre la militancia revolucionaria antes del golpe. Mientras el lenguaje de la izquierda resaltaba la calidad de "héroes" y "mártires" de los represaliados, los nuevos organismos comenzaron a hablar de "víctimas" de violaciones a los derechos humanos por parte del régimen represivo. Como sostiene Markarian (2004): "Esta prédica ponía el énfasis en la denuncia de los métodos del estado por encima de la exaltación de los atributos de los militantes" (p. 10). En otras palabras, esta forma de caracterizar los hechos, reemplazó las iniciativas de historización de los crímenes en clave de violencia política por la irrupción de una "narrativa humanitaria". De todas formas, como sostiene Débora D’Antonio (2017), en Argentina "ha existido históricamente una cultura de denuncia testimonial basada en una detallada descripción de la apli- 
cación de tormentos que la literatura materializó en obras célebres como Operación masacre de Rodolfo Walsh o La Patria fusilada de Paco Urondo" (p. 198).

Lo anterior explica, en parte, la presentación de los desaparecidos como "víctimas inocentes" que se instaló a partir de la última dictadura militar, diferenciándose de los reclamos anteriores donde se reivindicaba la condición de "políticos" de los presos. Como sostiene Carol Solis (2008), esto también se evidencia en la denominación de los nuevos organismos, en tanto que la mayor atención estuvo puesta en la identidad de los reclamantes ("madres", "abuelas", "familiares") más que en tipificar las categorías de los represaliados ("político", "gremial", "estudiantil"), como en las organizaciones previas a 1976. Crenzel (2013) también indica que la denuncia en clave humanitaria tenía estrecha relación con los denunciantes, en su mayoría familiares, para quienes su lazo con el desaparecido se basaba en valores humanitarios, ignorando sus adscripciones políticas o ejerciendo un silencio estratégico sobre ellas dada la persecución dictatorial.

Ahora bien, además de la identidad de los reclamantes, estas nuevas organizaciones carecían de los vínculos político-partidarios que habían tenido las anteriores, por las circunstancias ya descritas (el cercenamiento del espacio público; la imposibilidad de gestar los reclamos mediante organizaciones políticas y político-militares o sindicatos). Alonso (2017) advierte que:

La falta de referencias respecto de las corrientes políticas reprimidas operó en el sentido de una despolitización de la demanda y de su fijación en el puro resguardo de los derechos elementales. La apelación a la Declaración Universal y al "mito de la inocencia", según el cual los desaparecidos eran "víctimas inocentes" ajenas a la lucha armada, se complementó con la crítica de la violencia (p. 110).

No obstante, algunos militantes y dirigentes, especialmente de la izquierda armada, tardaron en advertir el alcance y las consecuencias de la escalada represiva y aún confiaban en el éxito a corto plazo de sus métodos de lucha. Además de esta confianza, como sostiene Markarian (2004) para el caso uruguayo, otros rasgos de la cultura política de la izquierda permiten explicar su relativo desinterés inicial por las actividades de denuncia: "En primer lugar, persistía una forma de entender la militancia que 'heroicizaba' el sacrificio y la entrega a la causa revolucionaria. También perduraba un cierto rechazo a expresiones sociales y políticas consideradas 'menores' por no ata- 
car la 'contradicción esencial' de la sociedad, ya expresada en términos de clase o en su versión populista de 'oligarquía versus pueblo" (p. 8).

Por otro lado, Crenzel (2013) sostiene que el requerimiento y el uso de la presentación de los desaparecidos comenzaron a estandarizarse entre los organismos argentinos a partir de los vínculos que establecieron con las redes transnacionales de derechos humanos. Según el autor, estas entidades proveyeron a las nacionales, entre otras cosas, modelos de formularios para tomar y ejercer las denuncias de los desaparecidos. Estos formularios fueron incorporados por la APDH de Buenos Aires en 1979 para sistematizar las denuncias recibidas con el fin de entregarlas a la CIDH en su visita al país. ${ }^{12}$ No obstante, es probable que tales formularios llegaran a otras ciudades del país con posterioridad..$^{13}$

Por otra parte, según Lorena Balardini (2015), en las formas de manejo de la documentación y producción de información, algunos familiares pusieron el foco, más que en la experiencia extranjera, en la condición "profesional" de "abogados" de las organizaciones de derechos humanos. Para la autora, "la sistematización de información se constituyó como una forma particular de práctica política de estas organizaciones en el marco de los procesos de rendición de cuentas correspondientes a las etapas analizadas, a partir de la estructuración y demarcación que imponen las reglas del campo jurídico”" ${ }^{14}$ (p. 92).

Markarian (2004), por otra parte, analiza que la operación de traspaso de una narrativa a otra, en el caso del senador uruguayo Zelmar Michelini ${ }^{15}$ se

${ }^{12}$ La CIDH llegó a Argentina en septiembre de 1979 para investigar las denuncias contra la dictadura militar y en su informe final -publicado en 1980 - se condenó a la dictadura responsabilizándola de las desapariciones forzadas, la aplicación sistemática de la tortura, la existencia de presos políticos sin proceso y otros abusos. La inspección del organismo dependiente de la ozA había sido impulsada James Carter, por entonces presidente de los Estados Unidos. Para más información véase D’Antonio, 2010.

${ }^{13}$ En Rosario, dado que para entonces la APDH todavía no había sido creada, comenzaron a utilizarse en los últimos años de la dictadura en el Equipo Jurídico coordinado por Delia Rodríguez Araya. Sobre la fundación de APDH en Rosario véase Scocco (2016a). Sobre su equipo jurídico y la abogada Delia Rodríguez Araya véase Scocco (2017) y Del Frade (2011).

${ }^{14}$ De acuerdo con la teoría de los campos sociales de Bourdieu (1987): "El campo jurídico es un espacio de competencia por el monopolio del derecho a determinar la ley. Dentro de este campo ocurre una confrontación entre actores que poseen herramientas técnicas que son inevitablemente sociales, y que consisten, esencialmente, en la capacidad socialmente reconocida de interpretar un corpus de textos, santificando la correcta o legitimada visión del mundo social” (p. 817).

${ }^{15}$ Michelini había fortalecido sus vínculos con organizaciones transnacionales de derechos humanos y consiguió una invitación para dirigirse al congreso de Estados Unidos en 1976 pero antes de que pudiera viajar, en mayo de ese año, fue secuestrado y asesinado en Buenos 
basó no sólo en experiencias internacionales sino también en tradiciones nacionales de respeto a los derechos individuales, presentando al autoritarismo como un quiebre sustancial con este legado.

Otra clara diferencia de estas organizaciones creadas a mediados de los años setenta era el concepto de preso político que tenían respecto del que he planteado en el apartado anterior, lo que es una muestra del cambio de época, pero también de la necesidad de generar empatía con la sociedad. En octubre de 1978, Familiares de Desaparecidos y Detenidos por Razones Políticas de Rosario realizaba un boletín público donde informaba sobre la situación del país y la constitución de Familiares en dicha ciudad, repetían los reclamos por los desaparecidos, solicitaban audiencia con autoridades militares y eclesiales y peticionaban por las condiciones de detención de los presos políticos. Allí se definía al detenido político de la siguiente manera: "Cuando un ciudadano sufre cárcel, sin ser imputado de ningún delito, sin que se lo encuadre en ninguna de las tantas leyes punitivas o represivas, y solo se encuentre a disposición del PEN [Poder Ejecutivo Nacional], se trata de un detenido político" (Familiares de Detenidos, 1978, p. 2). Esta diferencia en el concepto de preso político muestra también el traspaso discursivo del combatiente que comete un delito con una intencionalidad política para fines sociales hacia una narrativa humanitaria sobre la persona detenida sin causa ni proceso.

Por último, una dimensión menos estudiada para el Movimiento de Derechos Humanos argentino -aunque no por eso menos importante-que tuvo injerencia en la transnacionalización del reclamo, es la condición social de los represaliados y, por ende, de las organizaciones que tenían como condición fundamental el vínculo primario con el familiar desaparecido. En este sentido, a pesar de que una parte considerable de los detenidos y desaparecidos por la última dictadura militar (1976-1983) provenía de la clase obrera y sindical, la represión de las Fuerzas Armadas estuvo dirigida principalmente contra la juventud de clase media alta políticamente movilizada y organizada. El Movimiento de Derechos Humanos fue heredero de esta supuesta represión selectiva, conformándose mayoritariamente por familiares provenientes de esa clase media o media alta definida por su ubicación social y su nivel de ingresos. Esa condición social de los reclamantes facilitó el acceso a las redes transnacionales de derechos humanos. Como sostiene Alonso (2017):

Aires por las fuerzas represivas argentinas y uruguayas, junto a su colega parlamentario Héctor Gutiérrez Ruiz y a otros dos uruguayos. 
la extracción de clase, sumada al apoyo de organismos internacionales de los países centrales, otorgó al movimiento argentino una alta capacidad de interacción a distancia. Casi por definición, los movimientos de derechos humanos no están fijados a un territorio, sino que articulan relaciones entre espacios distantes. Ello puede relacionarse con la composición de clase del movimiento, ya que las clases medias y medias altas tienen una amplia disponibilidad de medios de conexión a distancia -al contrario de las clases populares (p. 123).

\section{LA INFLUENCIA DE LA TRANSNACIONALIZACIÓN DEL RECLAMO EN UN CASO LOCAL}

Habiendo analizado la influencia de las redes transnacionales de derechos humanos en la adopción de una narrativa humanitaria para los organismos de Argentina, ahora me detengo en lo ocurrido en una ciudad de dimensiones medianas, como es Rosario (provincia de Santa Fe), en comparación con Buenos Aires, la capital del país.

Una de las cuestiones que marcaron la influencia transnacional tiene relación con la posibilidad de denunciar las desapariciones tanto en foros internacionales como en organismos extranjeros. Un hito central lo marcó la visita de la CIDH al país en 1979.

Esta visita de la CIDH no se puede explicar sin analizar la confluencia entre actores del exilio con actores nacionales. No obstante, la mirada "nacional" estuvo, por lo general, fuertemente centrada en Buenos Aires (Jensen, 2010; Basualdo, 2017), desconociendo el esfuerzo que se hizo desde otras ciudades del país. A partir del trabajo de Familiares de Detenidos y Desaparecidos por Razones Políticas, analizo aquí el modo en que desde Rosario se intervino en esta visita y en la proyección de denuncias propias sobre la violación de derechos humanos, así como la participación en otras actividades internacionales.

La CIDH estuvo del 7 al 10 de septiembre de 1979 en Buenos Aires, del 10 al 14 en Córdoba, los días 14 y 15 en Tucumán, pasó por Rosario el 18 y regresó a la Capital Federal. Unos días antes del arribo a Rosario, una delegación de Familiares de Desaparecidos y Detenidos por Razones Políticas había viajado desde Rosario a Buenos Aires para denunciar ante el organismo internacional la represión desatada en el sur santafesino. Luego, cuando se confirmó que la delegación visitaría Rosario, planificaron una serie de actividades para llevar a cabo en la ciudad. Incluían "una gran campaña de esclarecimiento" 
y la búsqueda de una activa participación de distintos sectores de la opinión pública, la prensa oral y escrita, etc., a través de solicitudes, comunicados y distintas formas para lograr una amplia difusión del problema de los detenidos-desaparecidos y los detenidos por razones políticas y sociales. ${ }^{16}$ Por su parte, algunos familiares habían realizado anteriormente denuncias ante este organismo que motorizaron aquella visita.

A raíz de esa experiencia acumulada, posteriormente los organismos rosarinos participaron de otras actividades internacionales entre las que se destacó la intervención de Fidel Toniolli ${ }^{17}$-presidente de la filial Rosario de Familiares de Detenidos y Desaparecidos de Rosario- en la XXXVI Asamblea de la Comisión de Derechos Humanos de las Naciones Unidas, en Ginebra (Suiza), el 29 de febrero de 1980, donde se trató el tema sobre las Desapariciones Forzadas o Involuntarias. ${ }^{18}$

Por otro lado, pero dentro de la denuncia pública internacional que hicieron los familiares de desaparecidos de Rosario, se encontraban los intentos de comunicación con el papa Juan Pablo II. Entre junio y julio de 1980, el papa realizó la primera visita oficial a Brasil, en plena dictadura militar, durante el gobierno del general João Baptista Figueiredo. Allí viajaron los familiares de Rosario con la idea de hacerle entrega de una nota "para que una vez más haga oír su voz pidiendo VERDAD y JUSTICIA para los que llamamos 'desaparecidos' y sus familias". ${ }^{19}$ Algo similar intentaron el 12 de junio de 1982, cuando viajaron a Buenos Aires por la visita del papa a dicha ciudad.

${ }^{16}$ Planificación de las tareas concretas a realizar con motivo de la visita de la CIDH de la OEA. Familiares de Desaparecidos y Detenidos por Razones Políticas de Rosario. Julio de 1979. Colección Darwinia Gallicchio. Museo de la Memoria, Rosario.

${ }^{17}$ Fidel Toniolli, padre de Eduardo Toniolli, desaparecido el 9 de febrero de 1977. Fue presidente y fundador de Familiares de Detenidos y Desaparecidos por Razones Políticas y miembro de la ConAdep, ambos de la ciudad de Rosario. Falleció el 13 de octubre de 2002.

${ }_{18}$ Véase Informe del Grupo de Trabajo sobre las Desapariciones Forzadas o Involuntarias, Consejo de Derechos Humanos, onu. Recuperado de http://www2.ohchr.org/english/issues/disappear/docs/A-HRC-13-31_sp.pdf. La participación de Toniolli consta en una carta de Familiares a la filial de la APDH. Carta de Familiares de Detenidos y Desaparecidos por Razones Políticas de Rosario, 17 de marzo de 1980. Archivo APDH Rosario, Rosario. Gentileza de Norma Ríos.

${ }^{19}$ Carta dirigida a Su Santidad Juan Pablo II. Mayo-junio de 1980. Colección Darwinia Gallicchio. Museo de la Memoria, Rosario. Norma Vermeulen, Madre de Plaza de Mayo de Rosario, lo recordaba así: "Después cuando vino el Papa, en el año '80 vino a Brasil, Porto Alegre, y bueno alquilamos un colectivo que... era un colectivo... j26 horas de viaje! Para dormir una noche, para poder entregar en el Arzobispado una carta para el Papa, que nunca nos respondió. Y cuando volvimos, al día siguiente, yo tenía los pies así viste de estar tantas horas arriba un colectivo y esos colectivos sin comodidad, esos colectivos viejos. Después cuando vino acá a 
Entrados los años ochenta, cuando la dictadura comenzaba a mostrar grietas cada vez más grandes, el equipo jurídico de APDH de Rosario comenzó su trabajo para juntar testimonios y pruebas, con visión de futuro. Aparece a partir de este momento la relación entre el campo jurídico y las estrategias implementadas por los organismos. Fue cuando empezó a destacarse la figura de la abogada Delia Rodríguez Araya, quien comenzó a pensar en la posibilidad de un juzgamiento futuro, en diálogo y sintonía con lo que realizaba la APDH a nivel nacional, ya que el formulario que se utilizó para tomar los testimonios era similar al que se utilizaba en la APDH de Buenos Aires. Fue la etapa a nivel nacional en que se emprendió la tarea de sistematizar la información sobre los desaparecidos. Si bien los organismos de Rosario siempre se habían preocupado por registrar los testimonios, especialmente de los familiares, en este momento se produjo un cambio en la estrategia y la tarea se concentró en los sobrevivientes, que podían dar cuenta de los lugares donde habían estado secuestrados, las personas desaparecidas que habían podido reconocer allí y también la identidad de algunos represores. Como sostiene Balardini (2015):

La búsqueda del reconocimiento público de los hechos como delitos había llevado a enfocarse en las víctimas y las circunstancias de la desaparición o muerte que vincularan el hecho a un accionar oficial. En esta etapa se va más allá de esta caracterización inicial y se busca comenzar a identificar a miembros de las Fuerzas Armadas y de Seguridad como responsables de los hechos (p. 18).

En otras palabras, esa "narrativa humanitaria" heredera de las redes transnacionales más centrada en las características físicas de los desaparecidos para su búsqueda y en la descripción de los secuestros, comenzó a adquirir particularidades propias en la apertura de un contexto de posible juzgamiento a los responsables del terrorismo de Estado.

Por último, la transnacionalización del reclamo y el impacto internacional de la demanda de la vigencia de los derechos humanos facilitó a los organismos de derechos humanos una importante asistencia material a través de determinado financiamiento. Las organizaciones que se crearon en el exterior, con localizaciones diversas, en su mayoría estaban integradas por

la Argentina en el año '82 fuimos a Buenos Aires... jah eso sin contar las veces que fuimos al Ministerio del Interior". Vermeulen, N. (30 de mayo de 2008). Entrevista a Norma Vermeulen, realizada por Marianela Scocco, en Magliocca (2010). 
personas exiliadas pero formaron parte de las redes transnacionales. Como sostiene Silvina Jensen (2014), estos organismos organizaron su actividad pública en torno a dos pilares: la solidaridad y la denuncia. Con respecto a la primera, intentaron aportar asesoramiento jurídico y contención afectiva, pero especialmente enviaron dinero y otros materiales para presos políticos y familiares de detenidos y desaparecidos en el exilio, remitiendo donaciones a Argentina que eran canalizadas a través de sus homólogos en el país.

Sin embargo, lo que llegaba a Rosario era muy inferior en relación con lo ocurrido en conglomerados como Buenos Aires y La Plata. Los organismos de esta ciudad se vieron privados del acceso a la financiación, a la información y al valioso poder de presión que la transnacionalización del reclamo proveyó a los organismos de la capital del país.

El ejemplo más claro lo presentaron las Madres de Plaza de Mayo rosarinas, ${ }^{20}$ que fueron despojadas de la asistencia material que proporcionó la solidaridad internacional del reclamo a las Madres de Buenos Aires y La Plata e incluso a otros organismos rosarinos, como ocurrió con Abuelas de Plaza de $\mathrm{Mayo}^{21}$ y el MEDH. Tanto quienes las acompañaron como ellas mismas, siempre se encargaron de destacar que la delegación Rosario de Madres nunca recibió fondos económicos de otras instituciones, ni siquiera de la entidad central de la Asociación Madres de Plaza de Mayo. Como sostiene Ana Moro:22 "Para esa época todos se acercaban a Familiares. Me acuerdo de la venta del periódico de las Madres. Yo era la secretaria de Finanzas. Todo se hacía con mucho esfuerzo. Rosario nunca recibió ayuda económica, como sucedía con Buenos Aires" (citado en Del Frade, 2011, p. 248).

Sin embargo, existió una excepción, que vino de la mano del hijo de una de las Madres, Irma Molina, que se encontraba viviendo en el exterior y les envió dinero, hecho que fue muy cuestionado por las Madres porteñas. Según relata Inés Cozzi, abogada y militante en derechos humanos: "Cuando

${ }^{20}$ Sobre las Madres de Plaza de Mayo de Rosario, véase Scocco (2016b).

${ }^{21}$ A partir de la constitución de la filial de Abuelas de Rosario en febrero de 1984, esta comenzó a funcionar con todas las características que tiene una filial, entre las cuales se encuentra el soporte económico. Esta es una diferencia notable con la estructura de Madres de Plaza de Mayo, que no envió fondos económicos a sus delegaciones. Véase Scocco (2012).

${ }^{22}$ Ana Moro integró el grupo de Familiares de Detenidos y Desaparecidos por Razones Políticas de Rosario desde sus orígenes. Hermana de Miriam Moro, desaparecida y asesinada el 27 de septiembre de 1976, e hija de Nélida Moro, integrante de Madre de Plaza de Mayo de Rosario desde sus comienzos. 
se enteraron las Madres de Buenos Aires se enojaron mucho, porque dijeron que todas las donaciones eran para la casa central." ${ }^{\prime 3}$

Por otra parte, las regionales del MEDH también atendían las consecuencias sociales de la estrategia represiva, política y económica de la dictadura, facilitando asistencia financiera y técnica para los desempleados por razones políticas, sosteniendo comedores infantiles y articulando cooperativas de trabajo. La participación de actores provenientes del mundo religioso en estos organismos daba continuidad a viejas prácticas de solidaridad destinadas a integrar migrantes y dar asistencia a refugiados y desterrados. El carácter transnacional de sus propias organizaciones los situaba en un lugar privilegiado. Como sostiene María Soledad Catoggio (2014), es necesario considerar

la dimensión transnacional del mundo religioso como un elemento decisivo en la gestión de la circulación y los intercambios entre activistas y organizaciones humanitarias que hicieron frente a la represión estatal trascendiendo los límites del Estado. La trama religiosa funcionó como una plataforma común que facilitó la confluencia regional de activistas de Derechos Humanos de distintos orígenes nacionales e ideologías políticas. Los dotó de una infraestructura y de una serie de recursos (materiales y simbólicos) que fueron clave para la asistencia a las víctimas y sus familiares, la lucha antidictatorial y la incorporación de los actores locales al campo internacional de los Derechos Humanos (p. 193).

Para el pastor Hugo Urcola, ${ }^{24}$ al momento en que él llegó a Rosario en el año 1982, los organismos ya no eran considerados como organismos de denuncia sino de servicio social. Fundamentalmente el MEDH, que empezó a ayudar a los que comenzaban a retornar del exilio y sobre todo a los sobrevivientes, que salían de las cárceles y de los centros clandestinos de detención. Urcola era superintendente de la región santafesina y por lo tanto pastor de varias iglesias, pero por lo general las "ayudas" las entregaba en el templo "La Re-

${ }^{23}$ Entrevista a Inés Cozzi, realizada por Marianela Scocco, 12 de marzo de 2013. Rosario, Argentina.

${ }^{24}$ Hugo Urcola, obispo de la Iglesia Metodista Argentina, estuvo fuertemente involucrado en movimientos de derechos humanos, participó de la fundación del MEDH y miembro de la CoNADEP, ambos de la ciudad de Rosario. Urcola había participado de la formación de la APDH en la ciudad de La Plata, ciudad donde desempeñó el pastorado desde 1976 a 1982, cuando fue trasladado a Rosario. Ya había estado anteriormente como pastor en Rosario de 1965 a 1972 . Entrevista a Hugo Urcola, realizada por Marianela Scocco, 24 de marzo de 2015. Rosario, Argentina. 
surrección”, ubicada en Laprida 1453 de Rosario. Antes de otorgar el dinero, tanto exiliados como sobrevivientes debían responder una serie de preguntas y firmar la petición, hecho que molestaba mucho a personas que recién obtenían su libertad o habían sido muy perseguidas. Toda esa documentación era enviada a la central del MEDH en Buenos Aires, que suministraba los fondos económicos que luego entregaba Urcola personalmente.

El pastor hace mucho énfasis en la ayuda económica que brindó el MEDH a organismos y familiares y en los "canales del dinero": "Madres, Abuelas, Asamblea, el MEDH recibían mucho dinero, fundamentalmente de Europa, porque Europa tenía la prosperidad de la 'Cortina de Hierro' para acá, ahora cuando cae el muro de Berlín se corta toda esa ayuda que venía de Europa a los organismos y a las iglesias". ${ }^{25}$ Claro que se refiere a las sedes matrices de estos organismos que se ubicaban en Buenos Aires y que, en algunos casos, descentralizaban ese dinero y, en otros no, como vimos para los casos de Abuelas y Madres respectivamente. Sostiene Urcola:

El MEDH fue un gran organismo que ayudó prácticamente a los demás organismos, ese fue el servicio del MEDH, porque yo cuando estaba acá [Rosario], nosotros organizábamos colectivos que iban a Sierra Chica, a apoyar a los presos, y después trabajó mucho cuando empezaron a salir, y el retorno, la gente venía del exilio, ahí el MEDH jugó un rol muy importante, llegó a tener como 100 empleados. ${ }^{26}$

\section{A MODO DE CIERRE}

En este artículo reconstruí cómo, en Argentina -entre las dos últimas dictaduras militares- se produjo en las organizaciones defensistas de personas represaliadas un traslado de una "narrativa revolucionaria", que consistió en la denuncia de la cárcel como principal estrategia represiva de la dictadura, basada en una matriz política-ideológica de transformación social, y ponía el foco en el carácter de "políticos" de los presos, a otra narrativa influenciada

${ }^{25}$ Hugo Urcola, entrevista citada. Carlos Ochoa, militante en derechos humanos, también sostiene que: "Había gente que ayudaba financieramente, la cuestión de las finanzas era importante, la socialdemocracia europea ayudaba mucho hasta Malvinas”. Entrevista a Carlos Ochoa, realizada por Marianela Scocco, 24 de septiembre de 2016. Rosario, Argentina.

${ }^{26}$ Hugo Urcola, entrevista citada. 
por la transnacionalización de las denuncias denominada "humanitaria", que resaltaba la descripción de los secuestros y las torturas, las condiciones de los lugares de detención, la presentación de las características de los represaliados (nombres, edades y sexos, nacionalidades, creencias religiosas, ocupaciones y profesiones) y la identidad de los represores. De esta forma, los organismos de derechos humanos argentinos adoptaron una concepción de derechos individuales de alcance universal que en cierta forma despolitizaba el reclamo.

Pero además de los repertorios discursivos, las redes transnacionales en defensa de los derechos humanos proveyeron a las nacionales de diversos métodos para tomar y ejercer las denuncias de los desaparecidos. Uno de ellos fueron los formularios incorporados por la APDH de Buenos Aires en 1979 para sistematizar las denuncias recibidas con el fin de entregarlas a la CIDH. Sin embargo, es probable que tales formularios llegaran a otras ciudades del país, como Rosario, con posterioridad. Eso demuestra que esa "narrativa humanitaria" heredera de las redes transnacionales adquirió características propias en los diferentes lugares y en la apertura de un contexto de posible juzgamiento a los responsables del terrorismo de Estado.

Por último, interesa señalar que las formas de denuncia, manejo de la documentación y producción de información fueron también variadas y algunos familiares $\mathrm{y} / \mathrm{u}$ organismos pusieron el foco, más que en la experiencia extranjera, en la condición profesional de los abogados de las organizaciones de derechos humanos y en tradiciones nacionales relacionadas con los derechos individuales de las personas.

Esas diferencias regionales y temporales se profundizan al momento de analizar los canales de financiación que proveyó la solidaridad internacional del reclamo, donde se destaca que no llegaron de la misma manera a las agrupaciones fuera de los conglomerados de Buenos Aires-La Plata.

De esta forma, interesa resaltar que el estudio sobre casos regionales y locales permite agregar algunos condimentos al análisis de la influencia y también de las diferencias con las redes transnacionales en materia de derechos humanos en Argentina.

\section{LISTA DE REFERENCIAS}

Alonso, L. (2011). Luchas en plazas vacías de sueños. Movimiento de derechos humanos, orden local y acción antisistémica en Santa Fe. Rosario: Prohistoria Ediciones. 
Alonso, L. (2014). El estudio de las luchas pro derechos humanos en Argentina: problemas de enfoque en torno a la categoría de movimiento social. En P. Flier, Dilemas, apuestas y reflexiones teórico metodológicas para los abordajes en Historia Reciente. La Plata: Editorial de la Universidad de La Plata.

Alonso, L. (2017). Terror de Estado y luchas pro derechos humanos en Argentina: las dimensiones ocluidas. Ayer, 107(3), 99-124. Recuperado de http://revistaayer. com/articulo/164

Bacci, C., Carnovale, V. y Oberti, A. (2010). Abogados, derecho y politica. Buenos Aires: Memoria Abierta.

Balardini, L. (2015). Estrategias de producción de información de las organizaciones de derechos humanos en Argentina. Los usos de la sistematización y la estadística en la búsqueda de verdad y justicia. (Tesis de maestría inédita). Facultad de Ciencias Sociales-Universidad de Buenos Aires, Argentina.

Basualdo, G. (2017). La movilización internacional del CELs durante la última dictadura: la visita de la ciDH. Identidades, 7, 79-97.

Bourdieu, P. (1987). Theforce of law: Towards a sociology of the juridical field. Hastings Law Journal, 38(5). Recuperado de https://repository.uchastings.edu/ hastings_law_journal/vol38/iss5/

Brysk, A. (1994). La política de derechos humanos en Argentina. Protesta, cambio y democratización (trad. Isabel Inguanzo Ortiz). Stanford University Press.

Catoggio, M. S. (2014). La trama religiosa de las redes humanitarias y del activismo transnacional en las dictaduras del Cono Sur de América Latina. En S. Jensen y S. Lastra (eds.), Exilios: militancia y represión. Nuevas fuentes y nuevos abordajes de los destierros de la Argentina de los años setenta. La Plata: Editorial de la Universidad de La Plata.

Chama, M. (2010). La defensa de presos políticos a comienzos de los '70: ejercicio profesional, derecho y política. Cuadernos de Antropología Social, 32, 195-217. Recuperado de http://revistascientificas.filo.uba.ar/index.php/CAS/article/view/1434

Chama, M. (2014). Activismo social, militancia política y radicalización de los años sesenta. La experiencia de la Comisión de Familiares de Detenidos (CofAdE). En M. C. Tortti (dir.), La nueva izquierda argentina (1955-1976). Socialismo, peronismo y revolución. Rosario: Prohistoria Ediciones.

Cofade (1969). Libro negro de la Casa Rosada, Buenos Aires.

Cofappeg (1972). Torturas en Argentina. Córdoba.

Crenzel, E. (2008). La historia política del Nunca Más. La memoria de las desapariciones en la Argentina. Buenos Aires: Siglo XXI editores. 
Crenzel, E. (2013). Los derechos humanos, una verdad evidente de la democracia en la Argentina. Estudios, 29, 73-91. Recuperado de https://revistas.unc.edu.ar/index. php/restudios/article/view/5340

D’Antonio, D. (2010). Derechos humanos y estrategias de la oposición bajo la dictadura militar argentina. Tensões Mundiais, 6(11), 153-178. Recuperado de https:// revistas.uece.br/index.php/tensoesmundiais/article/view/656

D’Antonio, D. (2017). Vigilancia, control social y agencia política del activismo por los derechos humanos ante la llegada de la Comisión Interamericana de Derechos Humanos (Argentina, 1979). Izquierdas, 32, 184-202. DoI: http://dx.doi. org/10.4067/S0718-50492017000100184

Del Frade, C. (2011). Delia, la abogada militante. Rosario: Editorial La Comuna.

Eidelman, A. (2009). El PRT-ERP y la lucha por la libertad de los presos políticos, 1971-1973. Sociohistórica, 25, 13-39. Recuperado de http://sedici.unlp.edu.ar/ handle/10915/13746

Familiares de Detenidos y Desaparecidos por Razones Políticas de Rosario (18 de septiembre de 1978). Decimos. Rosario.

Foro de Buenos Aires por la Vigencia de los Derechos Humanos (1973). Proceso a la explotación y a la represión en la Argentina. Buenos Aires.

Jensen, S. (2010). Los exiliados. Las luchas por los derechos humanos durante la dictadura. Buenos Aires: Sudamericana.

Jensen, S. (2014). El descubrimiento de los derechos humanos en el exilio español. Los derroteros de Cosofam Barcelona en la lucha antidictatorial (1978-1983). En R. Kotler (comp.) El país del sí me acuerdo. Los orígenes nacionales y transnacionales del movimiento de derechos humanos en Argentina: De la dictadura a la transición. Rosario: Imago Mundi.

Keck, M. y Sikkink, K. (2000). Activistas sin frontera: redes de defensa en politica internacional. México: Siglo XXI.

Laino Sanchis, F. (2020). Salir al mundo en tiempos de dictadura: Abuelas de Plaza de Mayo y las redes transnacionales de derechos humanos (1977-1983). Quinto Sol, 24(1), 1-22. DoI: http://dx.doi.org/10.19137/qs.v24i1.2314

Magliocca, E. (guion y dirección) (2010). Arderá la Memoria. La historia de las Madres de Plaza 25 de Mayo de Rosario. [Documental]. Rosario, Argentina.

Mangiantini, M. (2018). La nueva izquierda en la Argentina. Claves y discusiones alrededor del concepto. Astrolabio, 21, 27-52. Recuperado de https://revistas.unc. edu.ar/index.php/astrolabio/article/view/21110

Markarian, V. (2004). De la lógica revolucionaria a las razones humanitarias: la izquierda uruguaya en el exilio y las redes transnacionales de derechos humanos 
(1972-1976). Cuadernos del CLAEH, 27(89), 85-108. Recuperado de https://publicaciones.claeh.edu.uy/index.php/cclaeh/article/view/130

Scocco, M. (2010). Las estrategias represivas en las dictaduras militares de los años setenta en el Cono Sur. Los casos de Uruguay, Chile y Argentina. Historia Regional, XXIII(28), 155-176. Recuperado de http://historiaregional.org/ojs/index.php/ historiaregional/article/view/82

Scocco. M. (2012). La historia de una búsqueda. Darwinia Gallicchio, Madre y Abuela de Plaza 25 de Mayo de Rosario. Aletehia, 3(5), 1-16. Recuperado de http://www. memoria.fahce.unlp.edu.ar/art_revistas/pr.5447/pr.5447.pdf

Scocco, M. (2016a). Búsqueda, denuncia y organización. Los comienzos de los organismos de derechos humanos en Rosario (1976-1982). Revista de Historia, 17, 224-246. Recuperado de http://revele.uncoma.edu.ar/htdoc/revele/index.php/ historia/article/view/1340

Scocco, M. (2016b). El viento sigue soplando. Los orígenes de Madres de Plaza 25 de Mayo de Rosario (1977-1985). Rosario: Editorial Último Recurso.

Scocco, M. (2017). La militancia de abogados en defensa de los derechos humanos a partir de la última dictadura militar en Rosario. Antecedentes, participación y pertenencias identitarias. Contenciosa, V(7), 1-15. Recuperado de http://hdl.handle.net/2133/16462

Scocco, M. (2021 en prensa). Defensa, solidaridad y apoyo a los presos políticos. La Cofappeg (1970-1976). Trabajos y Comunicaciones, 52.

Solis, C. (2008). Nombrarse y ser nombrado. Reflexiones acerca de la constitución histórica de la identidad 'familiares de'. Jornada sobre Identidades, Representaciones del Horror y Derechos Humanos, Córdoba.

\section{OTRAS FUENTES}

\section{Archivos}

Archivo APDH Rosario, Rosario.

Museo de la Memoria, Rosario. 